\title{
SABERES E FAZERES MUSICAIS APINAYÉ: O CASO DO RITUAL DO MEGRE MÔX
}

\section{APINAYÉ MUSICAL KNOWLEDGE AND PRACTICES: THE CASE OF MEGRE MÔX RITUAL}

\author{
Walace Rodrigues ${ }^{1}$
}

RESUMO: Este artigo nasce de nossos estudos entre os Apinayé para nossa pesquisa de doutorado entre os anos 2012 e 2015. Este texto objetiva refletir sobre quem são os Apinayé, sua história de contatos e os seus saberes e fazeres musicais observados na performance ritual do período final de luto (Megrẽ Môx em língua Apinayé). A metodologia utilizada foi bibliográfica e de observação de campo, tendo, nossa análise, um cunho qualitativo. Os resultados mostram que a riqueza cultural Apinayé pode ser observada em vários rituais e cerimônias realizados durante a estação seca e que os saberes e fazeres musicais deste povo indígena são essenciais para a continuação de tais eventos.

PALAVRAS-CHAVE: performance musical; ritual; música.

ABSTRACT: This paper is related to our studies among the Apinaye indigenous peoples for our doctoral research between the years 2012 and 2015. This text aims to bring up thoughts on who the Apinayé are, their history of contacts and their musical knowledge and practices as observed in the ritual performance of the final period of mourning (Megrẽ Môx in Apinayé language). The methodology used was bibliographic and that of field observation, having, our analysis, a qualitative nature. The results show that the Apinaye cultural diversity can be observed in various rituals and ceremonies performed during the dry season and that the knowledge and musical activities of this indigenous peoples are essential for the continuation of such events.

KEYWORDS: musical performance; ritual; music.

\section{Introdução}

Este artigo busca revelar um pouco sobre os saberes e fazeres dos Apinayé, povo indígena Timbira que vive no norte do Estado do Tocantins, na Amazônia Legal, e que detêm uma rica cultura

\footnotetext{
${ }^{1}$ Doutor em Humanidades pela Universiteit Leiden (Países Baixos). Pós-Doutor pela UnB/POSLIT. Professor da UFT e docente do PPG em Demandas Populares e Dinâmicas Regionais (PPGDire) e do PPG em Ensino de Língua e Literatura (PPGL). CAPES/CNPq. 
ancestral. Este trabalho tem como justificativa deixar conhecer uma população indígena amazônica, contribuindo para o entendimento da história de contato dos Apinayé como a sociedade nacional, bem como para o conhecimento de práticas tradicionais deste povo através do ritual Megrẽ Môx.

Nossa pesquisa para esse texto foi baseada em fontes bibliográficas e nossa reflexão buscou, qualitativamente, compreender um pouco sobre a vida e os fazeres e saberes musicais dos Apinayé. Este escrito utiliza os seguintes autores como base teórica: BASSO (1985), sobre performance ritual; BLACKING (2000) sobre "ordem sonora"; BOAS (1955), sobre relativismo

cultural; NIMUENDAJÚ (1983), sobre alguns aspectos culturais dos Apinayé; DAMATTA (1976), sobre aspectos socioculturais dos Apinayé; GIRALDIN (2001), sobre a organização social Apinayé; PADOVAN (2011), sobre a história da educação no norte do Tocantins; PIEDADE (2011), sobre performance e temporalidade indígenas; RIBEIRO (1983, 1987), sobre alguns aspectos culturais dos indígenas brasileiros; entre outras fontes.

Tomamos os saberes e fazeres musicais dos Apinayé como uma forma de linguagem artística, que aqui chamamos de performance ritual. Tais performances provocam acontecimentos que buscam produzir devires complexos na subjetividade cultural coletiva e individual dos performers. Para tanto, um jogo representacional de processos artísticos variados (de cantos ancestrais, das músicas instrumentais, de danças coreografadas, de espacialidades e temporalidades determinadas, de gestual simbólico, de uso de instrumentos musicais específicos, etc) gera novas possibilidades para o exercício da criatividade étnica dos Apinayé durante estas experiências culturais colaborativas.

Aqui também buscamos compreender um pouco da história de contatos dos Apinayé com os brancos, seus modos de vida e seus fazeres e saberes musicais através do sistema musical (instrumentos musicais e performances musicais) utilizados na celebração do Megrẽ Môx, um ritual específico que marca o período final de luto por um ente partido.

\section{Os Apinayé e um pouco de sua história de contatos}

Vale começar este texto deixando ver quem são os Apinayé e um pouso de sua história de contatos com os brancos. Eles são um povo indígena de aproximadamente 1.847 pessoas (de acordo com dados de 2010 da Fundação Nacional de Saúde - Funasa), mas já seriam bem mais na atualidade. Habitam principalmente o município de Tocantinópolis (no Estado do Tocantins) e suas redondezas e

Organon, Porto Alegre, v. 35, n. 70, p. 1-16, 2020. E-ISSN: 22388915 DOI: 10.22456/2238-8915.104553 
dividem-se em mais de 40 aldeias. A maioria dessas aldeias são derivadas das duas mais antigas: São José (antiga Bacaba) e Mariazinha. Vivem historicamente na região norte do Estado do Tocantins, entre os rios Araguaia e o Tocantins, região conhecida como o Bico do Papagaio. Tiveram suas terras demarcadas em 1985 após vários conflitos, sendo essas terras em torno de 140.000 hectares.

São um dos povos Jê Setentrional. Eles tiveram seus primeiros contatos foram com os Jesuítas no século XVII. Os jesuítas navegaram, a partir do século XVII, o rio Tocantins a fim de “descerem" indígenas para as aldeias do Pará. Conflitos entre os Apinayé e a população da região se estendeu por todo o século XVIII, acalmando-se um pouco com a criação de um povoado no século XIX. A criação do povoado de Boa Vista do Tocantins, fundado em 1831 e elevado à categoria de cidade em 1858, hoje atual município de Tocantinópolis, foi um ponto marcante no contato constante entre os Apinayé e os não indígenas, já que a proximidade entre as principais aldeias (em torno de cinco na época) e o povoado facilitava os contatos entre indígenas e não indígenas. Utilizamos, aqui, uma passagem do Instituto Socioambiental (ISA) sobre a situação populacional dos Apinayé na primeira metade do século XIX:

Em 1840, é fundada por Frei Vito ${ }^{2}$ uma missão em uma das aldeias Apinajé, estendendo sua influência a outras três, atingindo um total de cerca de três mil índios. A tradição oral do Apinajé não guarda lembrança deste aldeamento, fazendo menção à fundação de Boa Vista apenas a partir da chegada de Frei Gil Vilanova, em finais do século XIX. (ISA, 2012).

Relatos de viajantes exploradores do século XIX que se aventuraram pela antiga Província de Goiás, como os de François Castelnau (1810-1880), Auguste François César Prouvençal de Saint-Hilaire (1779-1853), Johann Baptist Emanuel Pohl (1782-1834), George Gardner (1812-1849) e Karl Von den Steinen (1855-1929) deixam ver os contatos dos exploradores científicos com os indígenas da região, incluindo os Apinayé.

François Castelnau relata seu encontro com os Apinayé, levado por um monge missionário e em algum momento da primeira década do século XIX. Ele relata o encontro com os indígenas, o uso de uma buzina e danças "diferentes":

Esta noite foi uma das mais interessantes que passei durante toda a minha viagem. Os índios nos rodearam a princípio, mas logo depois se mostraram mais reservados do que costumam ser os brasileiros. Como se não se dessem conta de nossa presença, deixaram-nos inteiramente à vontade. Todavia vimo-los reunidos à volta de um orador, que depois de tirar sons agudos com

\footnotetext{
2 Missionário capuchinho frei Francisco do Monte São Vitor (cf. PADOVAN, 2011, p. 88). 
uma espécie de buzina, falou-lhes com voz alta e em tom de recitativo. Entre os índios que tinham feito a viagem a Belém, achava-se um moço bastante inteligente, que falava um pouco de português e era conhecido na missão pelo nome de João Apinajé. Mostrou-se ele muito solícito para conosco, prontificando-se a nos servir de intérprete. Soubemos assim sermos nós o assunto das arengas do orador, que dizia à tribo estarmos sob a proteção dos chefes que, embora brancos, éramos amigos e que, finalmente, tínhamos estado no aldeamento vizinho, sem em nada tocar na ausência dos habitantes. Vozes de aprovação seguiram-se a esse discurso, que durara perto de uma hora. Como a lua principiasse então a iluminar a cena, as danças assumiram aspecto diferente, dispondo-se em fila longa uma parte dos guerreiros.(CASTELNAU, 1949, p. 349).

Também, Karl Von den Steinen relata a proximidade dos contatos entre os Apinayé e os não indígenas da região, além de comentar que os Apinayé faziam usos de espingardas, conforme a passagem abaixo:

Da investigação das tribos, conhecidas através da literatura, mais aparentadas com os suiás vê-
se que podem ser colocadas ao lado dos aponejicrãs, residentes ao sul da Província de
Maranhão, e dos apinajés, espalhados na região norte, situada entre o Tocantins e o Araguaia.
Estes últimos foram visitados por Castelnau. Nessa época eles fruíam tanto da civilização
quanto os nossos jurunas de hoje, pois mantinham relações com os brasileiros, fazendo
tranquilo comércio de trocas, conservando, em todo o caso, a sua independência e os seus
costumes bárbaros. Um grupo de apinajés chegou a residir no Pará. Ao lado de arcos e
machados de pedra, possuíam espingardas e ferramentas, usavam rodelas nas orelhas,
perfuravam o lábio inferior, mas tinham desistido do batoque dos lábios, motivo pelo qual
eram antigamente também chamados botocudos. (VON DEN STEINEN, 1942, p. 365,
negrito nosso).

No século XIX, de acordo com a historiadora Regina Padovan (2011), os Apinayé foram assolados por varíola e por conflitos locais pela posse da terra. Esses fatores fizeram com que a população Apinayé fosse reduzida numericamente e de forma drástica. Além disto, o processo de desterritorialização dos Apinayé foi fruto dos vários ciclos econômicos e de avanço nacional que se impuseram à região:

Pode-se aludir, grosso modo, que o processo de desterritorialização dos Apinayés realizou-se em diferentes etapas de ocupação da colonização, desde o século XVIII: a primeira, decorrente da instalação de um posto militar em São João das Duas Barras (atual São João do Araguaia) por parte do governo do Pará; a segunda, pela formação do povoado em Cachoeira das Três Barras (atual Itaguatins) no extremo norte de Goiás (região denominada como Bico do Papagaio), por parte dos maranhenses provenientes de Caxias; a terceira, no processo de conflitos com os colonos e forças portuguesas nas fronteiras entre São Pedro de Alcântara (atual Carolina) e a ilha da Botica, às margens do rio Tocantins. (PADOVAN, 2011, p. 47).

Os contatos mais permanentes com os não indígenas ocorreram no século XIX. Segundo o ISA, e de acordo com Raimundo José da Cunha Matos (1776-1839), comandante das armas de Goiás 
entre 1823 e 1926). Os Apinayé contavam com uma população de aproximadamente 4.200 pessoas nos começos do século XIX. Em 1859, de acordo com a visita de Vicente Ferreira Gomes (1805-1838) a uma das três aldeias Apinayé então existentes, o número de Apinayé era em torno de 2.000 pessoas; em 1897, de acordo com Henri Anatole Coudreaux (1859-1899, um explorador francês), eram 400; em 1928, segundo Curt Nimuendajú, eram em torno de 200 pessoas; em 1967 eram cerca de 253, de acordo com Roberto DaMatta; e a partir de 1977, segundo a linguísta Helen Waller, eram em torno de 364, voltando a crescer, até chegar atualmente a uma população de aproximadamente 2.000 indígenas $^{3}$.

Além disto, a utilização fluvial dos rios Tocantins e Araguaia como frentes de expansão territorial alterou a vida dos indígenas da região, incluindo os Apinayé, conforme nos informa Roberto DaMatta (1976):

[...] o Tocantins e o Araguaia sempre foram usados por várias frentes de expansão, servindo basicamente como conexão entre diferentes fronteiras. Assim, embora o rio tenha sido um agente poderoso no que diz respeito à descoberta de tribos indígenas do Brasil Central, é só a partir de 1900, quando as amplas perspectivas da exploração de produtos vegetais (especialmente da castanha-do-Pará - Bertholletia excelsa - e o babaçu) começam a se esboçar, é que suas margens vão servir como ponto de aglutinação populacional. (DAMATTA, 1976, p. $35)$.

No século XX a frente extrativista de babaçu veio a se juntar à pecuária como uma das principais atividades econômicas da região. Os indígenas envolveram-se, então, na coleta do côco de babaçu. Roberto DaMatta (1976) relata que, durante seus períodos entre os Apinayé, na década de 1970, a coleta de babaçu era a mais importante atividade econômica deste povo. Hoje a venda de produtos agrícolas em pequena escala (como mandioca, farinha de mandioca, abóboras, mel, entre outros produtos naturais), as pensões dos idosos e os salários de alguns trabalhadores Apinayé contratados por órgãos do governo são as principais fontes de renda deste povo.

Outro fator importante e que marca sua influência sobre os Apinayé é a região onde habitam e seu ambiente ecológico. Na região Norte do Brasil, região da bacia amazônica, onde habita a maioria dos indígenas nacionais, encontramos, segundo Berta Ribeiro (1991), as terras de várzea ou aluvionais (terras de enchentes e vazantes e fertilidade dos solos e das águas), as terras altas (com denso manto de florestas, mas sem muitos recursos da fauna aquática) e as áreas de cerrado, onde se encontram os Apinayé. Berta Ribeiro explica-nos como funciona este ambiente ecológico do cerrado, onde vivem os Apinayé:

\footnotetext{
${ }^{3}$ Estes dados numéricos são do Instituto Socioambiental (Disponível em: <http://pib.socioambiental.org/pt/povo/apinaye/61 $>$. Acesso em 09 de mai. de 2020).
}

Organon, Porto Alegre, v. 35, n. 70, p. 1-16, 2020. E-ISSN: 22388915 DOI: 10.22456/2238-8915.104553 
[...] o terceiro tipo é o que caracteriza a área dos cerrados do Brasil central, entrecortada por "florestas de galeria" ao longo dos cursos d'água. Nesta área, a caça é mais abundante. Os grupos indígenas que a habitam praticam a horticultura nas florestas de galeria e a caça e a coleta, na savana. A dispersão de unidades domésticas, durante a estação da seca, e sua aglomeração em grandes aldeias (de até 1.200 habitantes) nos períodos que se seguem à colheita, podem ser responsáveis por sua complexa organização social. (RIBEIRO, 1987, p. 66).

Ainda, o antropólogo Daniel Gross (1975, apud RIBEIRO, B., 1991) também nos dá uma definição geral do ambiente social do cerrado brasileiro e de alguns aspectos de distribuição espacial dos grupos que aí habitam:

As plantas circulares das aldeias, as metades permeáveis, os elaborados sistemas de transmissão de nomes, os grupos de idade e os eventos cerimoniais e esportivos, que tornaram famosas essas sociedades, podem ter servido de mecanismos culturais para integrar unidades andantes semi-autônomas em aldeias unitárias, anualmente reconstruídas, prevenindo conflitos entre os grupos, propiciando a distribuição de produto das roças através da aldeia, e mobilizando os guerreiros para defesa e ataque. (GROSS apud RIBEIRO, 1987, p. 66, negrito nosso).

Muitos destes aspectos descritos por Gross são reconhecíveis entre os Apinayé ainda na atualidade. Os mais reconhecíveis, a nosso ver, são as plantas circulares das aldeias, o sistema de metades sociais, o sistema intrincado de transmissão de nomes, a atividade esportivo-sobrenatural de corrida das toras (uma atividade que vem sendo revitalizada entre os Apinayé), a distribuição de produtos alimentícios na aldeia e uma vida cerimonial em plena revitalização, como no caso do ritual do Megrẽ Môx (uma celebração de fim de luto), que relataremos neste texto a partir de suas performances rituais musicais.

\section{Um pouco de teoria etnomusicológica e performance ritual}

Sobre as performances rituais musicais, vemos que a arte possibilita-nos criar mundos imaginários, onde o performer entrega sua vida a aquilo que artisticamente executa num determinado período de tempo e num lugar específico.

Vemos que cada artista detém qualidades ímpares dentro de sua forma de arte, pois os homens diferem em qualidades e deixam ver isso no que fazem. Richard Schechner, um teórico da performance artística e teatral contemporânea, define a performance como "comportamentos 
restaurados":

Performances marcam identidades, dobram o tempo, remodulam e adornam o corpo e contam estórias. Performances - de arte, rituais, ou da vida cotidiana - são "comportamentos restaurados", "comportamentos duas vezes experienciados", ações realizadas para as quais as pessoas treinam e ensaiam. (SCHECHNER, 2006, p. 28).

\section{Schechner diferencia que o que pode ser entendido como performance e enquanto}

performance, dependendo de como cada cultura classifica determinados comportamentos:

Existem limites para o que "é" performance. Mas quase tudo que existe pode ser estudado "enquanto" performance. Algo "é" performance quando os contextos histórico e social, a convenção, o uso, a tradição dizem que é. Rituais, jogos e peças, e os papéis da vida cotidiana são performances porque a convenção, o contexto, o uso, e a tradição assim dizem. Não se pode determinar o que "é" performance sem antes se referir às circunstâncias culturais específicas. Não existe nada inerente a uma ação nela mesma que a transforme numa performance ou que a desqualifique de ser uma performance. A partir da perspectiva do tipo de teoria da performance que proponho, toda ação é uma performance. Mas da perspectiva da prática cultural, algumas ações serão julgadas performances e outras não; e isto varia de cultura para cultura, de período histórico para período histórico. (SCHECHNER, 2006, p. 38).

Sobre a corrida de toras Apinayé, um outro tipo de celebração que também podemos chamar de performance, utilizamos uma passagem do website da Associação União das Aldeias Apinajé (Pempxà) que relata a preparação das toras para os festejos na época seca (principalmente em junho, julho e agosto), época de muita fartura das colheitas, poucas chuvas e muitos festejos culturais:

Neste mês de agosto aqui na terra indígena Apinajé, localizada no município de Tocantinópolis, Estado do Tocantins estamos celebrando a corrida da Tora Grande (ou Pàrkapê). Este ritual de passagem é realizado em homenagem as pessoas falecidas e acontece sempre no período do verão. No início os padrinhos e madrinhas da tora pagam os cantadores que vão cantar todas as noites no pátio da aldeia até de manhã. E também são escolhidas duas pessoas para fazer escavação do tronco de buriti na preparação da Tora Grande. Nesses rituais são servidos muitos alimentos produzidos nas roças como; batata, feijão, arroz, banana, farinha, macaxeira. Antigamente nessas celebrações eram consumidas muitas carnes de caça e peixes. Hoje em razão da escassez de caças e pescados, estamos comprando esses produtos na cidade. Durante o período da preparação da Tora Grande, em algumas aldeias estão sendo realizados serviços de broca e derrubada das roças familiares e todos os dias no período da tarde são realizadas corridas de toras pequenas num percurso de (3) três km entre as aldeias Brejinho e São José. As corridas de toras são realizadas por dois grupos de homens (ou dois partidos) que chamamos Wanhme e Katàm, que competem correndo com as (02) duas toras; vence o partido que chegar primeiro no pátio da aldeia. No próximo dia 30 de agosto de 2013 haverá uma grande celebração e a corrida final da Tora Grande, que no encerramento é colocada em cima das sepulturas das pessoas falecidas. (PEMPXÀ, 2013, s/p).

A partir dessa perspectiva cultural apresentada, podemos começar a pensar sobre as

Organon, Porto Alegre, v. 35, n. 70, p. 1-16, 2020. E-ISSN: 22388915 DOI: 10.22456/2238-8915.104553 
performances como circunstâncias culturais específicas e repetidas com determinados fins rituais, como nos mostrou Schechner, e sobre os saberes e fazeres musicais Apinayé envolvidos nestas performances.

Vimos, em nossa pesquisa de campo, que os artesãos de objetos musicais são reconhecidos por seu grupo étnico como tal, mestres em sua arte e detentores de um saber ancestral e tradicional que eles aprenderam e devem passar adiante. Berta Ribeiro (1983), em uma proposta de revitalização artesanal com alguns povos indígenas, nos deixa ver que ela se "utiliza" dos artesãos reconhecidos como mestres para repassar conhecimentos: "Nossa proposta a respeito do aprendizado artesanal é utilizar os melhores artesãos indígenas de cada tribo, reconhecidos internamente como tais, como professores de sua arte às gerações mais jovens" (RIBEIRO, 1983, p. 18).

Franz Boas (1955) vai se referir, por várias vezes, aos melhores artesãos reconhecidos em seus grupos com a palavra "virtuoso". Ele ainda nos diz que os artistas "primitivos" dificilmente copiam formas de outros artistas e que, se assim o fazem, o fazem por motivos de rígida simetria e repetições rítmicas ${ }^{4}$ precisas designadas por um determinado estilo que devem seguir (BOAS, 1955, p. 156-7). Mesmo dentro de determinado estilo rígido, um artista virtuoso cria inovadoramente, combinando elementos tradicionais de maneiras novas e criativas.

No caso dos instrumentos musicais, John Blacking (2000) mostra-nos que os princípios de confecção dos objetos musicais depende fortemente de um conhecimento cultural, ritual e sobrenatural do grupo. Daí que princípios culturais sejam determinantes na confecção de objetos para fazer música, onde a percepção de uma "ordem sonora" ("sonic order") deve existir na mente do artesão e/ou músico antes que exista música:

Quero enfatizar que qualquer avaliação da musicalidade do homem deve se basear nas descrições de um campo distinto e limitado do comportamento humano que chamaremos provisoriamente de "musical". A ordem sonora pode ser criada incidentalmente como resultado de princípios de organização não-musicais ou extramusicais, como a seleção de orifícios equidistantemente espaçados em uma flauta ou desgastes em um instrumento de cordas. (BLACKING, 2000, p. 11, tradução nossa).

Ainda pensando na confecção dos instrumentos musicais indígenas, Cláudio Zannoni e Pedro Paulo da Cunha Moura (2010) comentam sobre a sutileza espiritual da ligação entre a música e as concepções cosmológicas e sobrenaturais indígenas:

\footnotetext{
${ }^{4}$ De acordo com Acácio Tadeu de C. Piedade (2011, p. 18), “...na poética musical a repetição não é uma redundância (nos termos de uma teoria da informação) mas, sim, um princípio racional originário, presente não apenas nos discursos artísticos, mas também nas filosofias e cosmologias nativas".
}

Organon, Porto Alegre, v. 35, n. 70, p. 1-16, 2020. E-ISSN: 22388915 DOI: 10.22456/2238-8915.104553 
A música é mesmo esse veículo de comunicação entre os espíritos. O espírito de quem canta e o espírito de quem ouve, o espírito de quem toca e de quem é tocado através do instrumento. Quando uma pessoa canta ou toca algum instrumento, está apresentando seu espírito a quem puder ouvi-la. (MOURA; ZANNONI, 2010, p. 28).

Também, como verificamos em nossas entrevistas em campo, nem todo artesão que confecciona objetos musicais sabe confeccionar todos os tipos de instrumentos para fazer música. Como, por exemplo, seu Camilo, que era conhecido por confeccionar vários tipos de objetos musicais (principalmente maracás, chocalhos de fieiras e várias buzinas), enquanto seu Francisco Dias Apinagé somente confeccionava maracás e armas tradicionais. Isso parece demonstrar que cada artesão se dedica a confeccionar objetos específicos mais ligados a seus gostos, habilidades e aprendizados. Lembramos que a confecção de objetos musicais entre os Apinayé é uma tarefa estritamente masculina.

Esta escolha por confeccionar isto ou aquilo parece, também, marcar a individualidade artística de cada artesão Apinayé. O etnomusicólogo Alberto Ikeda (1997) fala-nos sobre esta individualização que os sons e a música nos permitem:

Todo ser humano possui uma identidade sonora, uma voz própria que o identifica, como se fosse uma impressão digital. Essa voz marca a individualidade de cada um. Extensivamente, podemos dizer que os grupos humanos, de certa forma, possuem a sua "voz" ou as suas "vozes", constituídas por exemplos de músicas, padrões rítmico-melódicos, formas harmônicas, instrumentos musicais, e outros elementos sonoros que os caracterizam. (IKEDA, 1997, p. 4).

A passagem anterior deixa ver que as produções humanas de grupos sociais próprios servem, mesmo em sociedades atuais, para individualizá-los, por mais distintos que sejam estes grupos. Os artesãos/performers indígenas de instrumentos musicais participam, de forma única, nesta individualização de seus grupos, pois transmitem em sua arte toda a ancestralidade, a engenhosidade e a beleza de seu grupo.

Podemos dizer, ainda, a partir de nossas pesquisas, que os instrumentos musicais Apinayé não são objetos mágicos dos curandeiros ou feiticeiros, mas de uso cerimonial do cantor, que os utiliza nas festividades e celebrações que reforçam a lógica social deste grupo e suas crenças sobrenaturais. Ainda, os artesãos devem ter um forte conhecimento deste mundo sobrenatural e das significações étnicas com as quais ele pode trabalhar para fazer dialogar estas esferas da vida.

A materialidade, as especificidades e a própria disponibilidade dos materiais para se trabalhar é fator primordial no ofício do artista indígena. Além disto, a disponibilidade em ensinar 
aqueles que o procuram é chave para um processo de perpetuação da memória ancestral de seu povo.

No caso dos Apinayé, como verificamos numa celebração de fim de luto (Megrẽ Môx ${ }^{5}$ ) na aldeia Patizal, no ano de 2012, um mesmo maracá era utilizado por vários cantores, porém este era de propriedade do cantor Zé Cabelo ${ }^{6}$. Os cantores se utilizaram do mesmo maracá durante todo o dia e durante toda a noite de cantorias e danças.

Durante o dia, várias mulheres se colocaram em fila perpendicular aos cantores e todos cantavam em um sistema de chamado (do cantor) e resposta (das mulheres e dos homens que se enfileiravam atrás do cantor). O cantor principal desta performance foi Zé Cabelo e ela aconteceu no pátio central (ingó) da aldeia Patizal. A fileira das mulheres respondia e dançava em um movimento de balanço leve de joelhos e antebraços, enquanto a fileira dos homens dançava e cantava do começo ao fim da fileira das mulheres, indo e voltando. Os homens marcavam o ritmo com o maracá e com as batidas dos pés. Em alguns momentos os homens paravam ao comando do cantor principal no ponto médio da fileira de mulheres, sempre de forma perpendicular.

Os cantores masculinos e as mulheres se revezaram durante o dia e a noite, mas foi Zé Cabelo (filho de um pai Krahô e mãe Apinayé) quem se sobressaiu de forma mais visível. Entre os Apinayé e outros Timbiras, os Krahô têm a fama de serem excelentes cantores. A dança e o canto duraram toda a noite, porém diminuindo em número de participantes, que se revezavam para descansar um pouco. Somente pela manhã bem cedo é que o canto e a dança acabaram. Comeu-se o moquém de carne bovina e mandioca e distribuíram-se os pertences do morto e outros regalos comprados especialmente para a ocasião.

As cantigas Apinayé entoadas durante o Megrẽ Môx rezavam sobre como o morto foi um bom homem, um bom pai, um bom caçador, como cuidava bem de sua família, enfim, somente lembrando do morto de forma saudosamente positiva. Não buscamos averiguar as letras das cantigas por nos interessar mais especificamente os instrumentos musicais.

\footnotetext{
${ }^{5}$ A cerimônia começa com o corte de cabelo dos parentes do morto, que é deixado sem cortar desde a morte do parente. Isto serve para recordar aquele que se foi. Quando acontece o Megrẽ Môx, a primeira coisa que se faz é cortar os cabelos durante a manhã do primeiro dia de rememoração. Já no final do corte dos cabelos, o cantor principal começa a entoar cantigas (sem uso de instrumentos musicais) que lembram o morto. A partir deste momento começa a dança e o canto no pátio central da aldeia, sempre acompanhados de um maracá. Esses cantos e danças duram toda a tarde, noite e madrugada e só terminaram quando o sol nasce.

${ }^{6}$ Os cantores devem ter um alto grau de conhecimento do repertório a ser executado. Zé Cabelo é, atualmente, o mais conhecido cantor Apinayé, sendo reconhecido dentro desta sociedade como um bom cantor. As mulheres mais velhas também são grandes conhecedoras das cantigas a serem entoadas.
}

Organon, Porto Alegre, v. 35, n. 70, p. 1-16, 2020. E-ISSN: 22388915 DOI: 10.22456/2238-8915.104553 
Vale aqui informar que na visão de Ellen Basso (1985), quando analisando as performances narrativas dos Kalapalo, o conceito de "ritual musical" marca, de maneira essencial, a performance ritual indígena, já que esta pesquisadora acredita que a música é a chave desencadeadora da performance ritual e que o som é a forma primariamente simbólica da experiência de uma performance (negrito nosso). No caso dos rituais musicais Apinayé, corroboramos com a visão de Basso.

Podemos considerar, então, que a música, durante os rituais indígenas, é uma forma de ação comunicativa que desperta e impulsiona todo o desenvolvimento da performance indígena. Utilizamos, aqui, uma passagem de Basso sobre o "musical ritual”: "O ritual musical vai além do mito, é claro, colocando em prática coletiva o que normalmente é compartilhado verbalmente e ocasionalmente entre apenas algumas pessoas, criando, assim, as condições para a comunicação total" (BASSO, 1985, p. 9, tradução nossa).

Para os Apinayé a música coloca-se como ponto central durante seus rituais, o que eles chamam de "festas de cultura". Tais festividades, na atualidade, são: festa da primeira chuva, dia do índio (19 de abril), casamento, tora grande, Megrẽ Môx e Krát. Somente se utilizam instrumentos musicais indígenas nas festas culturais ${ }^{7}$. Em todo ritual Apinayé há a presença de sua música (vocal, instrumental ou associadas) e cantada em língua Apinayé. As festas culturais Apinayé se separam das festas de caráter religioso católico, onde se cantam cantos católicos e em língua portuguesa, assim as dividem os próprios Apinayé. Portanto, a música é indispensável para as performances rituais Apinayé, como verificamos em nossas pesquisas de campo.

Acreditamos que todas as festividades praticadas pelos Apinayé, incluindo aquelas que foram incorporadas através do contato com a sociedade envolvente, acabam por serem festas culturais, já que estão incorporadas na vida desta sociedade. No entanto, seguimos aqui a lógica Apinayé de separar festas de cultura de festividades incorporadas posteriormente.

Vale ressaltar que nosso entendimento de cultura baseia-se naquele de Clifford Geertz, importando-se com as “dimensões simbólicas da ação social - arte, religião, ideologia, ciência, lei,

\footnotetext{
${ }^{7}$ Os próprios Apinayé dividem as festas culturais das festas populares. As festas culturais são, para eles, as festividades ligadas as suas tradições ancestrais, como o Megrẽ Môx, as festas de colheitas, os rituais de iniciação, entre outros. As outras festas são influenciadas pela sociedade envolvente, como uma apresentação de banda de forró, celebração de algum santo católico, etc. A nosso ver todas elas fazem parte da cultura Apinayé, pois foram incorporadas por esta sociedade e para ela fazem sentido serem celebradas.
} 
moralidade, senso comum" (2008, p. 21), revelando uma teia de significados estreitamente relacionados entre si em cada sociedade estudada. Daí Geertz compreender uma análise antropológica como a leitura de um texto, onde várias significações são encontradas e relacionam-se numa teia. Os elementos culturais não podem ser analisados, portanto, separadamente, mas em suas estreitas relações de dependência.

Além do já dito, o etnomusicólogo Acácio Tadeu Piedade (2011) desenvolve uma interessante hipótese sobre a filosofia nativa em relação à temporalidade durante a performance ritual indígena (com o uso essencial da música). Ele nos diz que:

O pensamento musical é uma expressão da cosmologia posta em ação na música, revelando concepções fundantes da filosofia nativa no âmbito da temporalidade. Portanto, o sistema musical tem também um caráter existencial, pois reporta a formas de temporalidade concebendo a finitude. E o sistema musical não está isolado: o pensamento que cria a diferença a partir destas operações mínimas atua no âmbito das artes. (PIEDADE, 2011, p. 18).

O pensamento musical de um povo indígena brasileiro pode ser, portanto, um dos pontos que Geertz enfatiza enquanto componente da teia de significações que engloba a cultura. As dimensões simbólicas da vida social de um grupo, neste caso os ritos e as expressões musicais, fazem parte do todo que engloba a cultura de tal sociedade.

\section{Descrevendo o ritual do Megrẽ Môx}

Descrevemos o que foi o Megrẽ Môx: O corte cerimonial de cabelo começou depois do almoço. Tal ritual foi experienciado por nós nos dias 10 e 11 de novembro de 2012 (apesar de não ser o período de seca na região, tal ritual caracteriza-se como uma festividade da época seca, do período sem chuvas), na aldeia Patizal, onde vivia a pessoa a ser lembrada. A data para o começo do ritual foi escolhida pela mãe do falecido. Todos os parentes mais próximos do morto deixaram seus cabelos crescerem por meses e os tiveram cortados neste dia. Essa "alteração" corporal marcava o luto daqueles que amavam o falecido e indicava socialmente que eles estavam ligados ao defunto. Vale informar que o enterro da pessoa morta pode ter ocorrido há meses, mas espera-se a época seca para realizar o Megrẽ Môx.

Os cantos e danças na parte central do pátio começaram à tarde, antes do pôr do sol. Durante toda a noite os performers cantaram, tocaram maracá e dançaram. Realizaram esta 
performance até o sol nascer. Marcadamente sobrenatural, esta performance unia dança, música instrumental e vocal e exaltava as qualidades do falecido. Era notória a reverência aos espíritos (karõ) no ritual, assim como a reverência ao sol (Mbudti) e à lua (Mbuduvríre) com relação à música, cantos e danças. O canto e a dança começam quando o sol se põe, prolongam-se pelo período de domínio da lua e terminam quando o sol se levanta. Lembramos aqui a relação do mito de criação Apinayé ${ }^{8}$ (sobrenatural) com os fatos da vida real (natural) e seus ciclos.

A posição dos cantores no pátio, durante toda a tarde e noite de performance ritual, a posição das mulheres cantoras e dançarinas, alinhando-se de maneira perpendicular aos cantadores e ao tocador de maracá masculino, já mostrava uma coreografia e musicalidade culturalmente definidas.

Os cantos reverenciavam como o morto caçava bem, como pescava bem, como era bom pai, bom amigo, bom irmão, etc., conectando o mundo dos vivos com o dos mortos e fechando um ciclo de luto que terminaria com o característico choro cerimonial Apinayé.

Os cantos aconteceram em forma de sessões de chamado e resposta, evidenciando uma atitude eminentemente social no canto. As significações étnicas e rituais dadas ao canto, à dança e ao choro marcam as cerimônias culturais deste povo. Também, pudemos perceber que o sistema musical Apinayé tem importante papel sobrenatural e social para este grupo.

O ritual termina com a oferta dos pertences do morto e de outros objetos comprados para serem ofertados aos participantes. Todos os "procedimentos" rituais seguiram regras precisas, onde cada gesto, canto e ação tinha uma significação e era de suma importância para a relação com o sobrenatural e de uma beleza única em suas ações performáticas. Os mais velhos eram os detentores dos saberes de como se executava tal ritual. A senhora, que encomendou este Megrẽ Môx para seu filho falecido, já era bastante idosa e compreendia bem como o ritual deveria acontecer.

Também, todos aqueles que cantaram e dançaram no pátio foram "pagos" pela senhora que havia encomendado os cantos e as danças. Ela organizou todo o ritual, comprou presentes para serem distribuídos e recebia as pessoas que chegavam. Enfim, esta senhora fazia questão de que toda a cerimônia seguisse os padrões etnicamente estabelecidos.

\footnotetext{
${ }^{8}$ Curt Nimuendajú (1983, p. 120-124) relata o mito da criação do povo Apinayé. Segue o mito: O sol (Mbud-ti) desceu à terra e a Lua (Mbuduvrí-re) desceu atrás (ambos são masculinos na mitologia Apinayé). Eles criaram na terra toda sorte de caça, árvores e arbustos, rios, duas mulheres para cozinhar para eles e fazer um roçado. Sol e lua plantaram cabaças (Lagenaria siceraria) na roça. Quando as cabaças cresceram, eles as jogaram no rio. Quando estas cabaças voltavam à tona, elas se transformavam nos Apinayé. A partir daí eles criaram as aldeias. A dualidade marca a mitologia Apinayé e torna-se parte da cultura deste povo.
} 
O Megrẽ Môx foi, em nossa experiência de campo, o ritual Apinayé mais completo que conseguimos presenciar. As performances musicais no pátio, os choros cerimoniais e o caráter extremamente sobrenatural do evento nos marcaram profundamente. Neste momento sentimos que a vida cultural Apinayé era algo forte e que a música era central na cultura Apinayé, pois a música interagia necessariamente com todos os outros elementos desta sociedade, dando sentido a ela.

Ainda, vale informar que as canções indígenas são saberes transmitidos de geração a geração, perpetuando uma tradição musical oral. Em geral, a utilização da voz e do canto são dominantes nas culturas indígenas, mas existe um muito variado instrumental de apoio. Na maioria das vezes a música é associada à dança ritual. O ritmo é fluente, em geral, binário ou ternário, às vezes alternado em um mesmo verso. A estrutura das composições é bastante variada e as repetições e variações têm um papel importante na música indígena.

No caso específico do Megrẽ Môx os saberes e fazeres de como executar a cerimônia, os cantos a cantar, as formas de dançar, as marcações de tempo para cada ação, os objetos empregados na performance ritual, e muitos outros conceitos próprio da cultura Apinayé foram empregados e efetivamente executados dentro do sistema musical deste povo.

Verificamos que a funcionalidade do Megrẽ Môx para a sociedade Apinayé é aquela de reafirmação da teia de significações culturais deste povo e como elemento festivo mais ligado à sua ancestralidade. Tal ancestralidade coloca-se, assim, como aspecto importante para os próprios Apinayé, pois faz com que, mesmo incorporando novas atividades festivas e relevantes para a sociedade, tenham conhecimento, respeito e orgulho de tais "festas de cultura", como eles mesmos dizem.

Como nos informou Acácio Tadeu Piedade (2011, p. 18), a temporalidade do Megrẽ Môx reaviva a nossa finitude enquanto seres viventes e reafirmam, socialmente, o sistema musical específico dos Apinayé. Daí a necessidade de uma descrição deste ritual, pois pode revelar, mais claramente, a riqueza musical dos Apinayé.

Acreditamos, ainda, que cada povo indígena brasileiro detêm a percepção de uma "ordem sonora" (BLACKING, 2000, p. 11) específica de seu grupo e de uma "identidade sonora" (IKEDA, 1997, p. 4) própria, dada através de objetos musicais criados por cada grupo, cantos específicos para situações particulares, incorporações sonoras diversas e formas de expressão corporal determinadas para cada situação sinestésica. Todos estes elementos de performance musical ritual acabam por revelar um sistema musical próprio para cada sociedade indígena brasileira, mostrando, também, a necessidade 
de compreensão dos diversos sistemas musicais existentes no Brasil, principalmente na região da Amazônia Legal, onde há um grande número de sociedades indígenas.

Finalmente, verificamos que toda a performance musical ritual experienciada no Megrẽ Môx abarcou pontos que Richard Schechner (2006, p. 28) deixou bem frisados: buscou marcar identidades, tentou replicar temporalidades, influenciou os corpos para a atividade ritual ensaiada, revelou comportamentos restaurados e contou estórias.

\section{Considerações finais}

Este texto buscou compreender um pouco sobre o que nos revelam as pesquisas em relação aos saberes e fazeres do povo Apinayé. Lembramos que os conhecimentos aqui apresentados somente foram possíveis através da gentileza deste povo para conosco, de seu acolhimento e de sua confiança em nosso trabalho de divulgação de sua cultura.

Verificamos que as celebrações culturais Apinayé estão em um processo de grande revitalização e que os mais velhos são peças-chave na execução destes rituais. Eles detêm os saberes em relação a todo o processo de execução de tais rituais, mas também sobre os fazeres necessários (como os objetos a serem utilizados, como, no caso de nossa pesquisa, os instrumentos musicais) à realização de tais celebrações culturais. Por isso, quanto maior o número de anciãos e anciãs em uma aldeia, maior será a probabilidade de haver performances rituais.

Vemos como importante registrar o acontecimento do Megrẽ Môx como uma performance ritual musical deste povo, pois engloba música instrumental, dança, canto, pintura corporal, procedimentos e conhecimentos mitológicos e culturais específicos para seu acontecimento.

Ainda, é de extrema necessidade realizar estas celebrações culturais para que os mais jovens tenham acesso a elas, conheçam seus significados e particularidades para cada povo indígena. Tal atitude faz com que a cultura Apinayé passe de geração a geração, mesmo em um mundo com tantas situações exteriores que afetam o território (locus de fundamental importância para cada povo) e a cultura dos povos indígenas.

Concluindo, entendemos que o relato aqui apresentado não se acaba neste texto, mas deve instigar mais pesquisadores a buscarem conhecimentos junto aos povos indígenas do Tocantins, divulgar tais conhecimentos e deixar ver a riqueza cultural existente entre os inúmeros povos indígenas

Organon, Porto Alegre, v. 35, n. 70, p. 1-16, 2020. E-ISSN: 22388915 DOI: 10.22456/2238-8915.104553 
brasileiros.

\section{REFERÊNCIAS}

ASSOCIAÇÃO UNIÃO DAS ALDEIAS APINAJÉ (PEMPXÀ). Cultura. A preparação da tora grande. 13 de agosto de 2013. Disponível em: < http://uniaodasaldeiasapinaje.blogspot.com/2013_08_11_archive.html >. Acesso em 09 de mai. de 2020.

BASSO, Ellen B. A Musical View of the Universe: Kalapato Myth and Ritual Performance. Pennsylvania: University of Pennsylvania Press, 1985.

BLACKING, John. How musical is man? 6th ed. Seattle: University of Washington Press, 2000.

BOAS, Franz. Primitive Art. New York: Dove Publications Inc., 1955.

NIMUENDAJÚ, Curt. Os Apinayé. Belém: Museu Paraense Emílio Goeldi, 1983.

DAMATTA, Roberto. Um mundo divido: A estrutura social dos Apinayé. Petrópolis: Vozes. 1976.

GEERTZ, Clifford. A interpretação das culturas. $1^{\mathrm{a}}$ ed., 13a reimpr. - Rio de Janeiro: LTC, 2008.

GIRALDIN, Odair. Um Mundo Unificado: Cosmologia, Vida e Morte entre os Apinayé. Campos: Revista de Antropologia Social. 2001, v. 1, p. 31 a 46. Disponível em: < http://ojs.c3sl.ufpr.br/ojs2/index.php/campos/article/viewArticle/1567 >. Acesso em 09 de mai. de 2020.

INSTITUTO SOCIOAMBIENTAL (ISA). Povos Indígenas no Brasil. Disponível em: < http://pib.socioambiental.org/pt/povo/apinaye >. Acesso em 09 de mai. de 2020.

MOURA, Pedro Paulo da Cunha; ZANNONI, Cláudio. A música dos povos indígenas do Maranhão. Cadernos de Pesquisa. UFMA, São Luís, volume 17, nº. 3, set/dez. 2010, pág. 28 a 36.

PADOVAN, Regina Célia. Lugar de escola e "lugar de fronteira”: a instrução primária em Boa Vista do Tocantins em Goiás no século XIX (1850-1896). Tese de Doutorado apresentada no Programa de Pós-Graduação em Educação da Universidade Federal de Goiás (UFG), Faculdade de Educação, 2011.

PIEDADE, Acácio Tadeu de C. Análise musical e contexto na música indígena: a poética das flautas. TRANS - Revista Transcultural de Música/Transcultural Music Review. Número 15, 2011, pág. 1 a 22.

RIBEIRO, Berta G. Artesanato indígena: para que, para quem? IN: RIBEIRO, Berta G. E Outros. $O$ artesão tradicional e seu papel na sociedade contemporânea. Rio de Janeiro: FUNARTE/Instituto Nacional do Folclore, 1983, pág. 11 a 28. 
RIBEIRO, Berta G. O índio na cultura brasileira. Rio de Janeiro: Editora Revan, 1987.

RODRIGUES, Walace. O processo de ensino-aprendizagem Apinayé através da confecção de seus instrumentos musicais. Doutorado em Humanidades. Universiteit Leiden, 2015, 240 p.

SCHECHNER, Richard. O que é performance?. IN: Performance studies: an introduccion. $2^{\mathrm{a}}$ ed. New York \& London: Routledge, 2006, pág. 28 a 51.

VON DEN STEINEN, Karl. O Brasil Central. Expedição em 1884 para a exploração do Rio Xingu. Tradução de Catarina Baratz Cannabrava. São Paulo: Cia. Editora Nacional, 1942. 